\title{
Chapter 21 \\ The Relationship Between the Structure and Calcification of Dentin and the Role of Melatonin
}

\author{
Hiroyuki Mishima, Saki Tanabe, Atsuhiko Hattori, Nobuo Suzuki, \\ Mitsuo Kakei, Takashi Matsumoto, Mika Ikegame, Yasuo Miake, \\ Natsuko Ishikawa, and Yoshiki Matsumoto
}

\begin{abstract}
The present study aimed to examine the relationship between the structure and composition of dentin and odontoblasts and the role of melatonin during the calcification process. The expression of MT1 and MT2 melatonin receptor was confirmed in the odontoblasts of the control group. In addition, the expression of MT1 was stronger than that of MT2. A strong expression of MT1 was detected in the odontoblasts in the melatonin-treated groups. MALDI-TOF MS analysis revealed that two peaks of $795 \mathrm{~m} / \mathrm{z}$ and $818 \mathrm{~m} / \mathrm{z}$ were found in dentin. These peaks increased commensurately with the amount of melatonin. The number and size of calcospherites in predentin increased in proportion to the concentration of melatonin. The degree of mineralization increased slightly in the melatonin-treated group using CMR analysis. Two peaks could be clearly detected in the melatonin-treated
\end{abstract}

\footnotetext{
H. Mishima $(\triangle)$

Department of Dental Engineering, Tsurumi University School of Dental Medicine,

Yokohama, Japan

e-mail: mishima-h@tsurumi-u.ac.jp

S. Tanabe

Central Clinical Engineering Section, Osaka City General Hospital, Osaka, Japan

e-mail: mrc.skww02@icloud.com
}

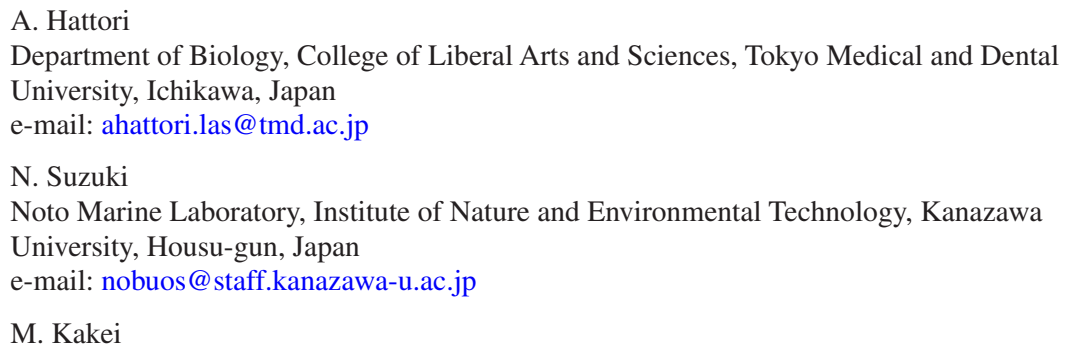


group at nighttime using X-ray diffraction analysis. Melatonin may participate in the dentin composition and the calcification mechanism of dentin.

Keywords Dentin $\cdot$ Melatonin $\cdot$ Melatonin receptor $\cdot$ Calcospherite $\cdot$ Calcification - Circadian rhythm

\subsection{Introduction}

In the hierarchy of internal biological rhythms, there are the circadian rhythm (circadian cycle: about $24 \mathrm{~h}$ ), the circalunar rhythm (about 28 days), and the circannual rhythm (about 1 year) (Koukkari and Sothern 2006; Mishima et al. 2013; Pfeffer et al. 2012). There is also circadian rhythm in the concentrations of $\mathrm{Ca}$ and $\mathrm{P}$ of the blood. It is reported that $\mathrm{Ca}$ will deposit on teeth and bones because blood $\mathrm{pH}$ tends to be alkaline and blood Ca value decreases at night (Ishida et al. 1983). It became clear that circadian rhythm is shown in oral tissues including salivary glands (Papagerakis et al. 2014).

Melatonin is the synchronization factor of circadian rhythm (Hattori 2017; Koukkari and Sothern 2006). One of the effects of melatonin is the adjustment of circadian rhythm, and it serves as the transmission material of the information at the nighttime. The melatonin synthesis changes between day and night. In the daytime, the melatonin amount decreases (Hattori 2017; Koukkari and Sothern 2006; Pfeffer et al. 2012). Melatonin is also associated with tooth development (Kumasaka et al. 2010; Tachibana et al. 2014). Melatonin may play an essential role in regulating bone growth (Roth et al. 1999; Satomura et al. 2007). When melatonin was administered in aged rats, the bone mass increased, and the internal structure of the bone was reinforced (Tresguerres et al. 2014). Antiaging effect of melatonin is expected (Hattori et al. 2006; Hattori 2017). Many of the physiological functions of melatonin are exerted via two melatonin receptors (MT1 and MT2) of the cell membrane

\footnotetext{
T. Matsumoto

Department of Laboratory Diagnosis, University Hospital, Nihon University School of Dentistry at Matsudo, Matsudo, Japan

e-mail: matsumoto.takashi@nihon-u.ac.jp

M. Ikegame

Department of Oral Morphology, Science of Functional Recovery and Reconstruction, Graduate School of Medicine, Dentistry and Pharmaceutical Sciences, Advanced Research Center for Oral and Craniofacial Sciences, Okayama University, Okayama, Japan e-mail: ikegame@md.okayama-u.ac.jp

Y. Miake

Department of Histology and Developmental Biology, Tokyo Dental College, Tokyo, Japan e-mail: miake@tdc.ac.jp

N. Ishikawa $\cdot$ Y. Matsumoto

Applied Life Science Course, Faculty of Agriculture, Kagawa University, Takamatsu, Japan e-mail: s18g604@stu.kagawa-u.ac.jp; myoshiki@med.kagawa-u.ac.jp
} 
(Pfeffer et al. 2012; Hattori 2017). MT1 is involved in the transmission of optical information and works on hypnosis, and MT2 is involved in synchronizing the circadian rhythm (Liu et al. 2013). MT1 is also involved in tooth development and formation (Kumasaka et al. 2010; Mishima et al. 2014; Tachibana et al. 2014). Melatonin may regulate various physiological functions in the body and is synchronized with diurnal change (Hattori 2017; Koukkari and Sothern 2006; Shimozuma et al. 2011). We have reported that an increase or decrease in the melatonin secretion influences the incremental line and formation of dentin (Mishima et al. 2013, 2014, 2015). The present study aimed to examine the relationship between the structure and composition of dentin and odontoblasts and the role of melatonin during the calcification process.

\subsection{Materials and Methods}

\subsubsection{Ethics}

These animal experiments were conducted with the approval of the animal laboratory ethics committee of the Meikai University School of Dentistry (Approval No. A 1019, A 1105, A 1221, A1525) and Kagawa University (Approval No. 17636). Animal experiments were conducted in compliance with the animal experiment implementation regulations of the Meikai University School of Dentistry and Kagawa University.

\subsubsection{Materials}

In this experiment, 5-, 6-, and 7-day-old SD rats were used. These rats were divided into three groups: (1) a control group (0.5\% alcohol-containing water), (2) a lowconcentration group ( $0.5 \%$ alcohol $+20 \mu \mathrm{g} / \mathrm{ml}$ melatonin-containing water), and (3) a high-concentration group ( $0.5 \% \mathrm{alcohol}+100 \mu \mathrm{g} / \mathrm{ml}$ melatonin-containing water). Before and after childbearing, melatonin was administered for 8 days at the 5-dayold rats, 9 days at the 6-day-old rats, and 10 days at the 7 -day-old rats. The slaughter was carried out at midday and midnight. The samples taken during the day were classified as daytime specimens, and specimens taken at night were classified as nighttime specimens. 


\subsubsection{Methods}

These samples were removed together with the jaw bones around the incisors. These were fixed in $10 \%$ neutral buffered formalin solution. The demineralized specimens were decalcified for 1 week with a $0.5 \%$ EDTA decalcification solution. The demineralized specimens were made into the sliced continuous sections with the thickness of about $4 \mu \mathrm{m}$ with a microtome. The sliced sections were stained with HE staining for the analysis of calcospherites and dentin structure. Immunostaining of the melatonin receptor was performed, and the localization of the melatonin receptor in the tissue was searched. The melatonin receptors were used, the melatonin 1a (MT1, Biorbyt, Cat\# orb11085, USA) and melatonin 1b (MT2, LifeSpan BioSciences, Cat\# LS-A934, USA). The immunohistochemistry procedure was carried out according to the method of Mishima et al. 2016. The staining sections were observed and analyzed using the light microscopy (ECL-IPSE80i, Nikon, Japan).

On the ground sections, one single-side polishing and double-side polishing were carried out with a grinding stone, a diamond lapping film (final particle size $3 \mu \mathrm{m}$ ), and a diamond paste (final particle size $0.25 \mu \mathrm{m}$ ). These ground sections were observed and analyzed by a light microscopy (Eclipse 80i, Nikon, Japan), a polarizing microscopy (Eclipse LV100N, Nikon), a scanning electron microscope (SEM, JSM-6500F, JEOL, Japan), a contact microradiography (CMR, Softex CMRK, Japan), an atomic force microscopy (AFM, Nanosurf Easyscan, Nanosurf, AG, Switzerland), X-ray diffraction method (RINT2500, Rigaku, Japan), and a mass spectrometry (matrix-assisted laser desorption ionization time-of-flight mass spectrometer: MALDI-TOF MS, ultrafleXtreme-KG1, Bruker, USA). Measurements of the number of calcospherites in predentin and the expression concentration of melatonin receptor in odontoblasts were performed using image analysis software WinROOF (MITANI, Japan). The measurement and analysis procedure were carried out according to the method of Mishima et al. (2014, 2016). The labial dentin covered the enamel, and lingual dentin covered the thin cementum in incisor. We observed and analyzed both dentins. The statistical significance between the control and melatonin-treated groups was assessed by Bonferroni correction and by Tukey's test. In all cases, the selected significance level was $p<0.05$ and $p<0.01$. The Ca, $\mathrm{P}$, and $\mathrm{Mg}$ concentrations in blood serum of rats in the control group and melatonintreated groups were analyzed using a SPOT-Chem blood analysis (SPOTCHEM EZ SP-443, ARKRAY, Japan).

\subsection{Results}

The number of calcospherites increased in the melatonin-treated group of 6-day-old rats in the nighttime specimens (Fig. 21.1). A significant difference was observed between the control group and the high-concentration group (Fig. 21.1, ${ }^{*} p<0.05$ ). However, no clear difference was found between the control group and the 


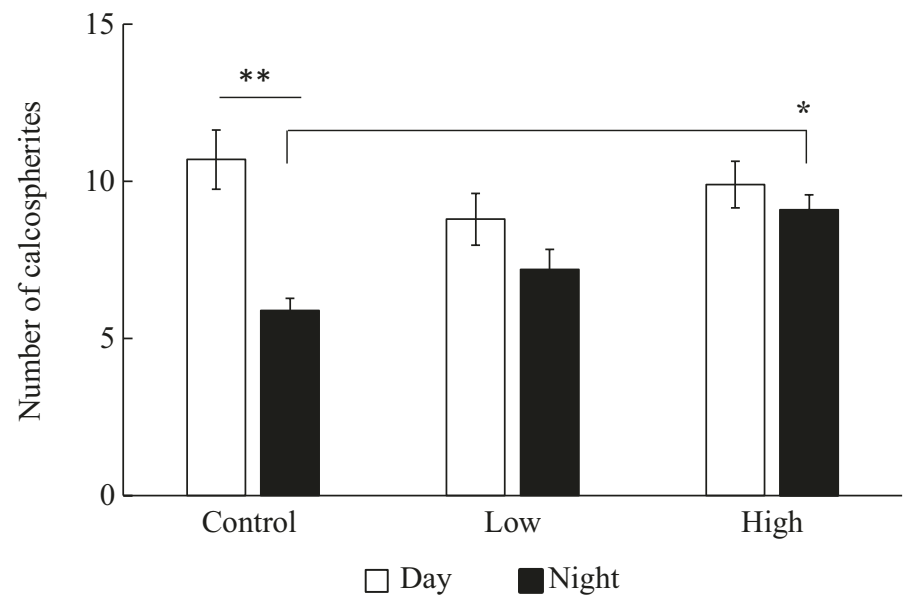

Fig. 21.1 Number of calcospherites in predentin. These data were obtained from the result of HE staining. In the nighttime specimens, calcospherites increased in the melatonin-treated group. 6-days old. Lingual dentin. $* p<0.05, * * p<0.05$
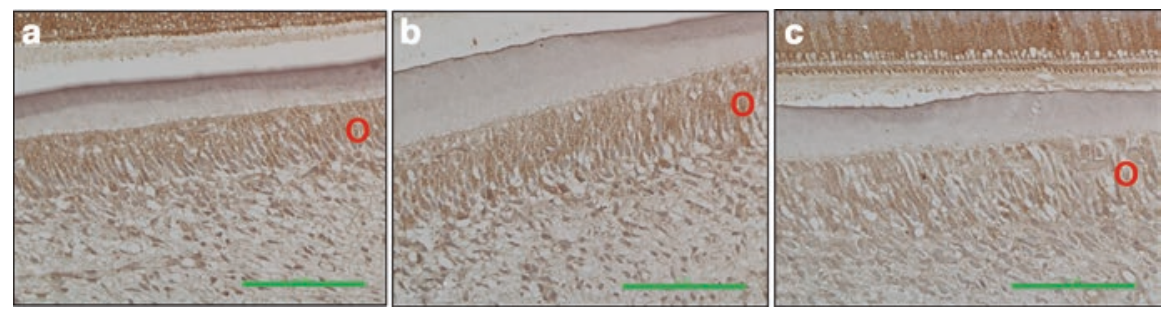

Fig. 21.2 Immunohistochemistry micrographs of the expression of MT1 melatonin receptor at the nighttime. The strong expression of MT1 in odontoblasts was detected in the high groups. 6 days old. Labial dentin. (a) High group, (b) low group, (c) control group. $O$ odontoblast. Scale bar, $100 \mu \mathrm{m}$

melatonin-treated groups in the daytime specimens. A significant difference was observed between the daytime and nighttime specimens in the control group (Fig. 21.1, ** $p<0.05$ ). The expression of MT1 and MT2 melatonin receptor was confirmed in the odontoblasts of the control group. In addition, the expression of MT1 was stronger than that of MT2. As compared with the control group (Fig. 21.2c), the strong expression of MT1 was detected in the melatonin-treated groups in the nighttime specimens (Fig. 21.2a, b). A significant difference was observed between the daytime and nighttime specimens in the high-concentration group (Fig. 21.3, ${ }^{*} p<0.05$ ). The difference in interference color (arrows) was found for the layers of incremental lines in the high-concentration group in the nighttime specimens (Fig. 21.4a). No change in interference color was observed in the control and lowconcentration group (Fig. 21.4b, c). By the backscattered electron image of SEM, the diameter of calcospherites of the control group was 10-18 $\mu \mathrm{m}$ (Fig. 21.5a), and 


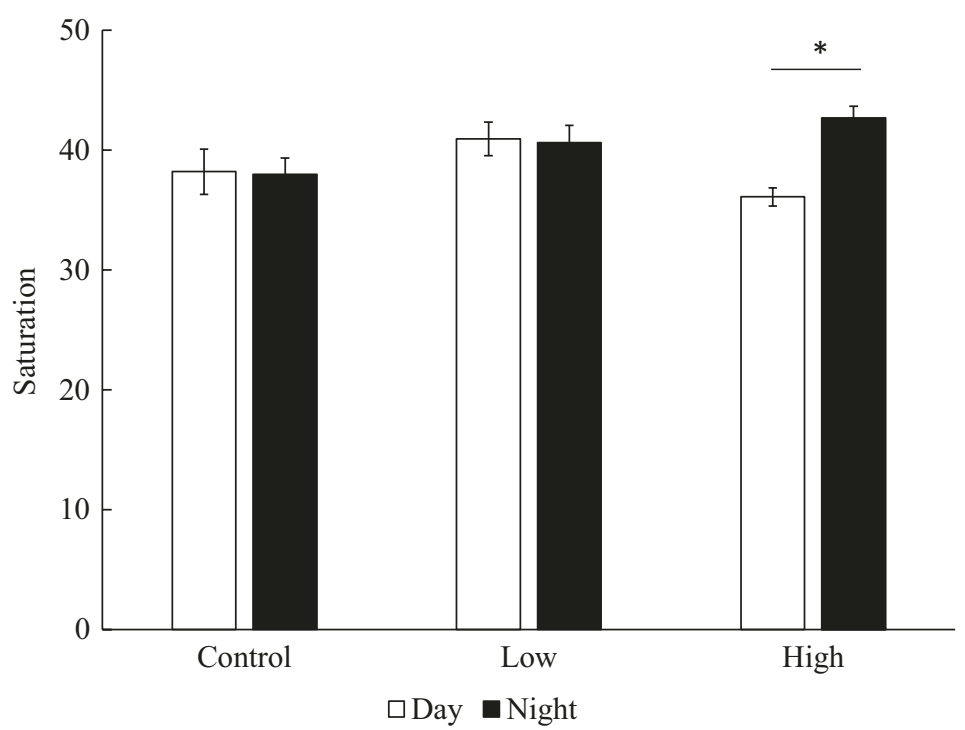

Fig. 21.3 Expression concentration of MT1 melatonin receptor in odontoblasts. The expressions of MT1 of the low and high group were somewhat stronger than that of the control group. The vertical axis represents saturation (range, $0-255$ ). $* p<0.05$
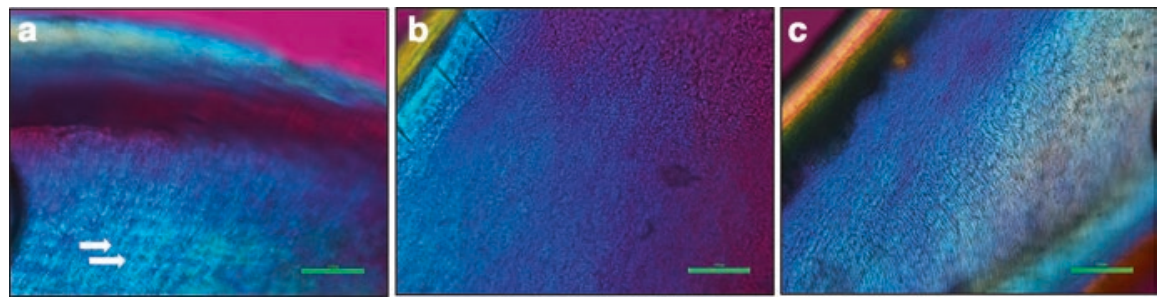

Fig. 21.4 Micrographs of polarizing microscopy of labial ground dentin. The difference in the interference color was found in the layer of incremental lines of the high group (arrows). 6 days old. (a) High group, (b) low group, (c) control group. Scale bar, $100 \mu \mathrm{m}$

that of calcospherites of the high group was 13-25 $\mu \mathrm{m}$ (Fig. 21.5b). The size of calcospherites in predentin increased in proportion to the concentration of melatonin. By the CMR images, calcospherites increased in the high-concentration group as compared with the control group (Fig. 21.6, arrow). On the degree of mineralization (mineral-volume \%), the control group was $29.00 \%$, the low-concentration group was $32.29 \%$, and the high-concentration group was $32.61 \%$. The degree of mineralization increased slightly in the melatonin-treated group. On the AFM images of ground section, the crystal surfaces of dentin were observed (Fig. 21.7ac). The crystal surface of dentin regularly arranged with globular uniform size in the high-concentration group (Fig. 21.7c). The diameter on crystal surface in the highconcentration group was $161-258 \mathrm{~nm}$. On the results of X-ray diffraction method, 

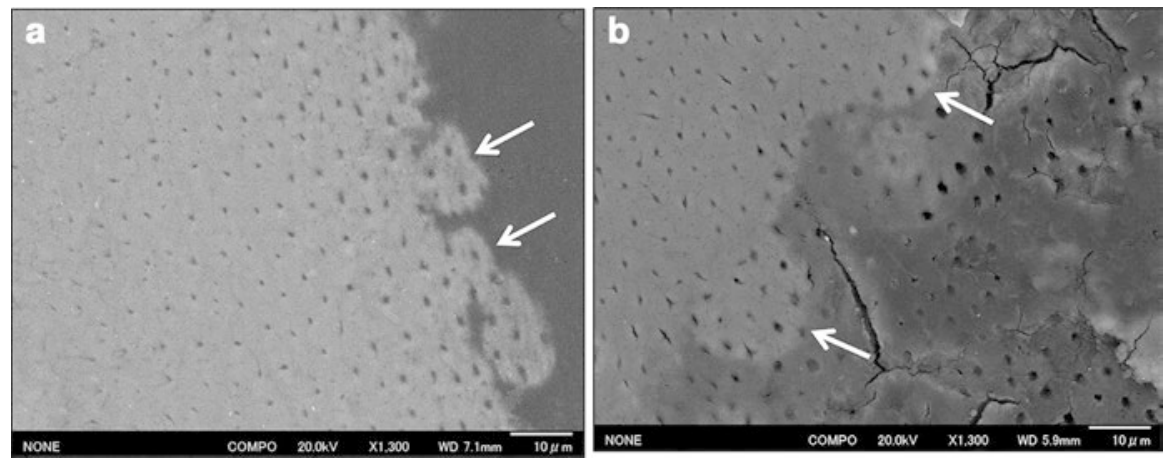

Fig. 21.5 Calcospherites in predentin using the backscattered electron image of SEM. The size of calcospherites in predentin increased in proportion to the concentration of melatonin. 7 days old. (a) Control group, (b) high group. Arrows: calcospherites. Scale bar, $10 \mu \mathrm{m}$
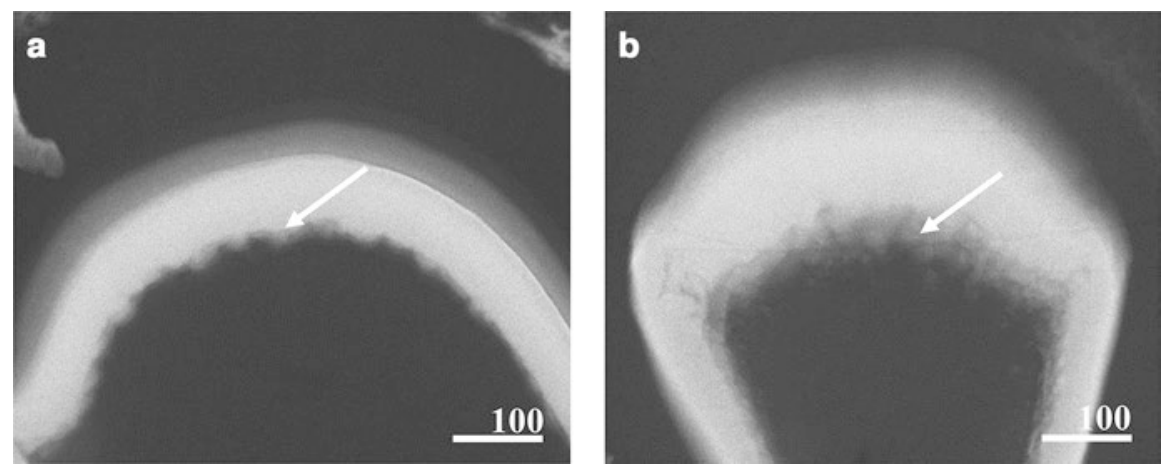

Fig. 21.6 CMR images of the transverse sections of incisor dentin. Calcospherites increased in the high group. The degree of mineralization increased slightly in the high group. The difference in thickness of dentin on (a) and (b) is due to the difference in the cutting region. 6 days old. (a) Control group, (b) high group. Arrows show calcospherites. Scale bar, $100 \mu \mathrm{m}$

one peak of crystal plane index was detected in the control group (Fig. 21.8a). However, two peaks of crystal plane indices were detected in the high-concentration group in the nighttime specimens (7-days old) (Fig. 21.8b). The low-angle plane index is (002), and the other plane index is one in which three plane indices (211), (112), and (300) overlap.

MALDI-TOF MS analysis of the ground sections revealed that two peaks of $795 \mathrm{~m} / \mathrm{z}$ and $818 \mathrm{~m} / \mathrm{z}$ were found in dentin. As the dose of melatonin increased, the detected intensity increased in the nighttime specimens (Fig. 21.9). There was no clear difference in daytime specimens. Figure 21.10 shows the results of $\mathrm{Ca}, \mathrm{P}$, and $\mathrm{Mg}$ concentration in blood serum using the SPOT-Chem blood analysis. A significant difference was observed between day and night in the control group on the concentration of $\mathrm{P}$ (Fig. 21.10, ${ }^{*} p<0.01$ ). However, the concentration of $\mathrm{P}$ in the melatonin-treated group did not differ between day and night. The difference was 

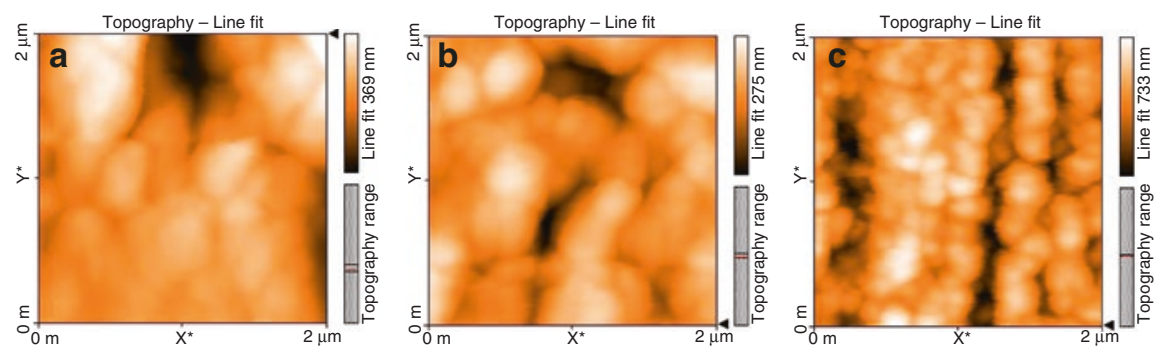

Fig. 21.7 AFM images of longitudinal ground section of dentin. The crystal surface of dentin arranged irregularly both control and low groups. The crystal surface of dentin regularly arranged with uniform size in the high group. 7 days old. (a) Control group, (b) low group, (c) high group. Length of $\mathrm{X}$ axis and $\mathrm{Y}$ axis, $2 \mu \mathrm{m}$
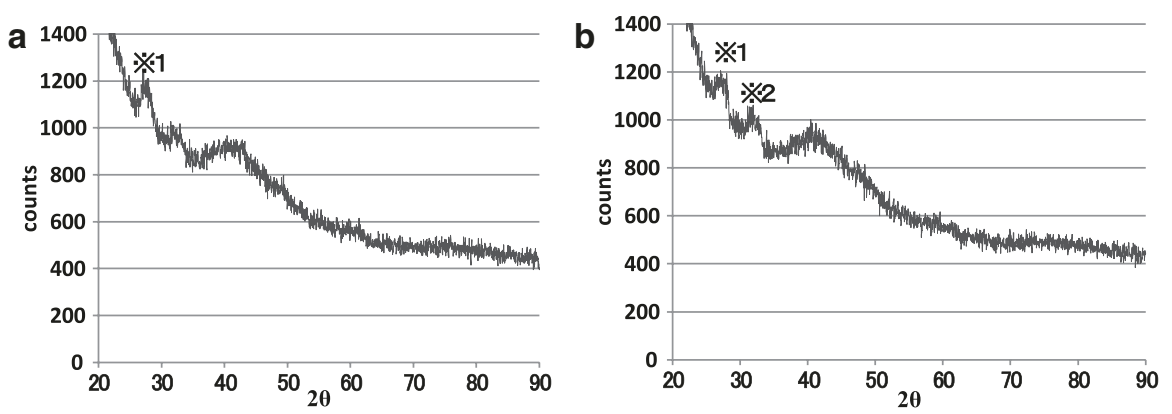

Fig. 21.8 X-ray diffraction patterns of dentin. Two peaks could be clearly detected in the high group at the nighttime. 7 days old. (a) Control group, (b) high group. $※ 1$ shows (002) and $※ 2$ shows (211), (112), and (300)

observed between day and night in the high-concentration group on the concentration of $\mathrm{Ca}$, but there was no significant difference $(p=0.08)$. The concentration of $\mathrm{Ca}$ and $\mathrm{P}$ in the blood serum changed by melatonin administration. Regarding the concentration of $\mathrm{Mg}$, there was no change.

\subsection{Discussion}

From HE staining and SEM observation, the number and size of calcospherites in predentin increased in the melatonin-treated group. By CMR analysis, the calcification was higher in the melatonin-treated groups. Ca and P content of dentin were higher in the melatonin-treated group (Mishima et al. 2013, 2014, 2015). The distribution density of $\mathrm{Ca}$ and $\mathrm{P}$ was greater in the melatonin-treated group (Mishima et al. 2015). The width of dentinal tubules was narrower than that of the control (Mishima et al. 2015). It is likely that the formation of peritubular dentin was promoted by melatonin (Mishima et al. 2015). From the X-ray diffraction and AFM 


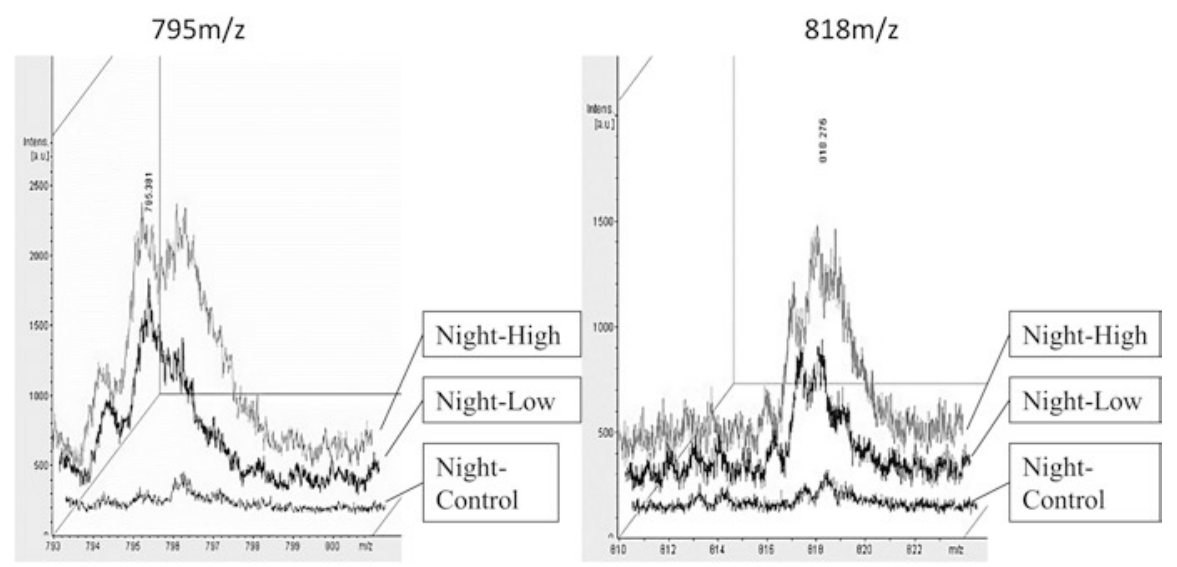

Fig. 21.9 Results of MALDI-TOF MS analysis. Two peaks of $795 \mathrm{~m} / \mathrm{z}$ and $818 \mathrm{~m} / \mathrm{z}$ are found in dentin at nighttime. As the dose of melatonin increased, the detected intensity increased. 6 days old. The vertical axis represents intensity (0-2500), and the horizontal axis represents $\mathrm{m} / \mathrm{z}$ (793-893)
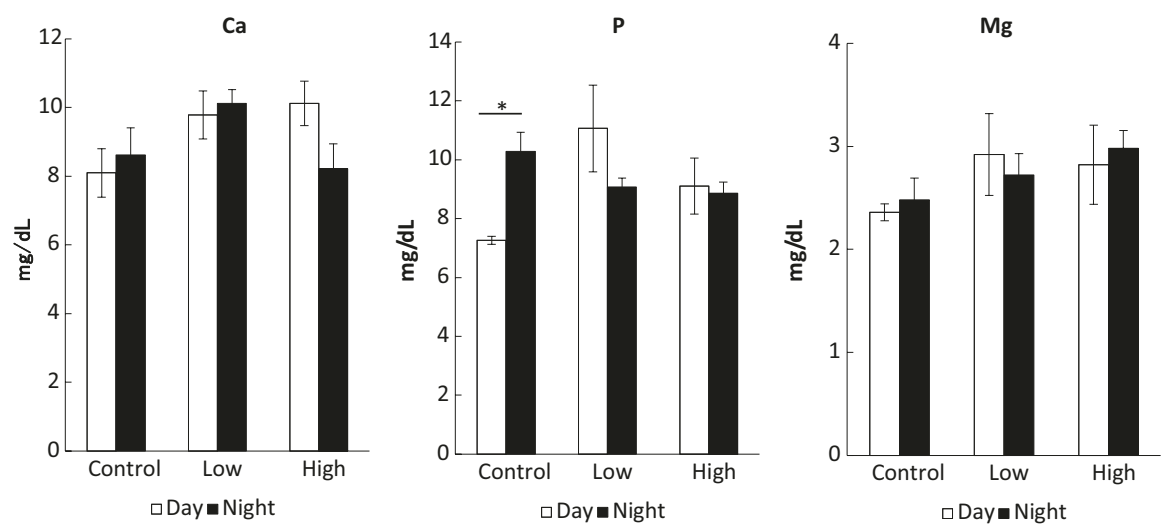

Fig. 21.10 $\mathrm{Ca}, \mathrm{P}$, and $\mathrm{Mg}$ concentration in blood serum using the SPOT-Chem blood analysis. From the left figure, the results of $\mathrm{Ca}, \mathrm{P}$, and $\mathrm{Mg}$ are shown. 7 days old. The vertical axis represents $\mathrm{mg} / \mathrm{dL} . * p<0.01$

analyses, it was considered that the crystallinity and orientation of the apatite crystal of dentin improved by administration of melatonin. We think that odontoblasts were activated by melatonin administration and promoted the dentin calcification.

From the result of the polarizing microscopy, it is considered that melatonin causes a change in the structure of dentin apatite crystals and collagen fibers. The Korff's fibers were more clearly distributed in the melatonin-treated group of nighttime and daytime specimens (Mishima et al. 2016). It is considered that the odontoblasts were activated by melatonin, and the secretion of collagen fibers was promoted. Mature dentin is made up of approximately $70 \%$ inorganic material, $20 \%$ 
organic material, and $10 \%$ water by weight. The organic phase of dentin is composed mainly of type I collagen (Nanci 2003). In mass spectrometry, the peaks of type I collagen are detected at $653-960 \mathrm{~m} / \mathrm{z}$ in the bone (Schweitzer et al. 2009). The MALDI-TOF MS analysis revealed that two peaks of $795 \mathrm{~m} / \mathrm{z}$ and $818 \mathrm{~m} / \mathrm{z}$ were found in dentin. Two peaks are considered to be the peptides in which the type I collagen has been resolved. These detected peaks intensity increased in the melatonin-treated groups. Thus, it is estimated that the peptides which a large amount of collagen was metabolized and resolved increased in the melatonintreated group. We thought that administration of melatonin promotes collagen secretion of odontoblasts and the collagenation of dentin.

A strong expression of MT1 was detected in the odontoblasts in the melatonintreated groups. MT1 is considered to be involved in the formation and development of teeth (Mishima et al. 2015). Kumasaka et al. (2010) and Tachibana et al. (2014) report the expression of MT1 in odontoblasts. Melatonin is thought to affect physiological functions of odontoblasts in the daytime and nighttime. It was suggested that the expression of MT1 depends on the amount of melatonin and that melatonin is efficiently incorporated into odontoblasts. Melatonin administration changed the behavior of $\mathrm{Ca}$ and $\mathrm{P}$ concentration in serum at night. In summary, the present study suggests that melatonin changed the blood composition in the body and influenced the structure, calcification, and crystallinity of dentin.

Acknowledgments The work was supported by JSPS KAKENHI Grant Number15K11034. This study was performed under the cooperative research program of the Center for Advanced Marine Core Research (CMCR), Kochi University (16A006, 16B006, 17A009, 17AB009). Regarding the image of AFM, we were aided by Dr. E. Yoshida of Tsurumi University School of Dental Medicine.

\section{References}

Hattori A (2017) Melatonin and aging. Comp Phys Biochem 34:2-11

Hattori A, Suzuki N, Somei M (2006) Melatonin up to date-melatonin effect on bone. Antioquia Med 2:78-86

Ishida M, Yamaoka K, Tanaka Y, Satomura K, Kurose Y, Yabuchi H (1983) The circadian rhythms of blood ionized calcium in humans. Scand J Clin Lab Invest 43:83-86

Koukkari WL, Sothern RB (2006) Introducing biological rhythms. Springer, New York 655 p

Kumasaka S, Shimozuma M, Kawamoto T, Kawamoto T, Mishima K, Tokuyama R, Kamiya Y, Davaadorj P, Saito I, Satomura K (2010) Possible involvement of melatonin in tooth development: expression of melatonin 1a receptor in human and mouse tooth germs. Histochem Cell Biol 133:577-584

Liu R, Fu A, Hoffman AE, Zheng T, Zhu Y (2013) Melatonin enhances DNA repair capacity possibly by affecting genes involved in DNA damage responsive pathways. BMC Cell Biol 14:1. https://doi.org/10.1186/1471-2121/14/1 http://biocellbiol.biomedcentral.com/articles/10.1186/1471-2121-14-1, (cited 2015-11-5)

Mishima H, Inoue M, Kadota R, Hattori A, Suzuki N, Kakei M, Matsumoto T, Satomura K, Miake Y (2013) The connection between the periodicity incremental lines of tooth dentin and the secretion rhythm of melatonin of the signaling molecules of biological clock. J Jpn Assoc Regen Dent 11:27-39 
Mishima H, Kadota R, Osaki M, Hattori A, Suzuki N, Kakei M, Matsumoto T, Ikegame M, Miake Y (2014) Analytical and histological studies on the changes of composition and structure of dentin by melatonin medication. J Jpn Assoc Regen Dent 12:11-22

Mishima H, Osaki M, Takeuchi S, Takechi K, Hattori A, Suzuki N, Kakei M, Matsumoto T, Ikegame M, Miake Y (2015) The influence that melatonin gives in dentin histology, the odontoblasts and the period of incremental lines of dentin. J Jpn Assoc Regen Dent 13:2-14

Mishima H, Takeuchi S, Tanabe S, Hattori A, Suzuki N, Kakei M, Matsumoto T, Ikegame M, Takechi K, Miake Y (2016) Effect of biological rhythm synchronous factor melatonin on structure, composition, and calcification of dentin and odontoblasts. J Jpn Assoc Regen Dent 13:2-14

Nanci A (2003) Dentin-pulp complex. In: Nanci A (ed) Ten Cate's oral histology: development, structure, and function. Mosby, St. Louis

Papagerakis S, Zheng L, Schnell S, Sartor MA, Somers E, Marder W, McAlpin B, Kim D, McHugh J, Papagerakis P (2014) The circadian clock in oral health and diseases. J Dent Res 93:27-35

Pfeffer M, Rauch A, Korf HW, von Gall C (2012) The endogenous melatonin (MT) signal facilitates reentrainment of the circadian system to light-induced phase advances by acting upon MT2 receptors. Chronobiol Int 29:415-429

Roth JA, Kim B-C, Lin W-L, Cho M-I (1999) Melatonin promotes osteoblast differentiation and bone formation. J Biol Chem 274:22041-22047

Satomura K, Tobiume S, Tokuyama R, Yamasaki Y, Kudoh K, Maeda E, Nagayama M (2007) Melatonin at pharmacological does enhances human osteoblastic differentiation in vitro and promotes mouse cortical bone formation in vivo. J Pineal Res 42:231-239

Schweitzer MH, Zheng W, Organ CL, Avci R, Suo Z, Freimark LM, Leblue VS, Duncan MB, Heiden MDV, Neveu JM, Lane WS, Cottrell JS, Horner JR, Cantley LC (2009) Biomolecular characterization and protein sequences of the Campanian hadrosaur B. canadensis. Science 324:626-631

Shimozuma M, Tokuyama R, Takehara S, Umeki H, Ide S, Mishima K, Saito I, Satomura K (2011) Expression and cellular localization of melatonin-synthesizing enzymes in rat and human salivary glands. Histochem Cell Biol 135:389-396

Tachibana R, Tatehara S, Kumasaka S, Tokuyama R, Satomura K (2014) Effect of melatonin on human dental papilla cells. Int J Mol Sci 15:17304-17317

Tresguerres IF, Tamimi F, Eimar H, Barralet J, Preito S, Torres J, Calvo-Guirado JL, FernándesTresguerres JA (2014) Melatonin dietary supplement as anti-aging therapy for age-related bone loss. Rejuvenation Res 17:341-346

Open Access This chapter is licensed under the terms of the Creative Commons Attribution 4.0 International License (http://creativecommons.org/licenses/by/4.0/), which permits use, sharing, adaptation, distribution and reproduction in any medium or format, as long as you give appropriate credit to the original author(s) and the source, provide a link to the Creative Commons license and indicate if changes were made.

The images or other third party material in this chapter are included in the chapter's Creative Commons license, unless indicated otherwise in a credit line to the material. If material is not included in the chapter's Creative Commons license and your intended use is not permitted by statutory regulation or exceeds the permitted use, you will need to obtain permission directly from the copyright holder.

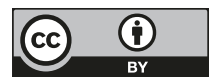

